\title{
Lung Cancer, Covid-19 Infections and Chemotherapy
}

\author{
BOGDAN HAINEALA ${ }^{1}$, ANCA ZGURA ${ }^{2}$, DUMITRU CRISTINEL BADIU ${ }^{3}$, LAURA ILIESCU ${ }^{4}$, \\ RODICA MARICELA ANGHEL ${ }^{2}$ and XENIA ELENA BACINSCHI ${ }^{2}$ \\ ${ }^{1}$ Department of Urology, "Fundeni" Clinical Institute, \\ "Carol Davila" University of Medicine and Pharmacy, Bucharest, Romania; \\ ${ }^{2}$ Department of Oncology-Radiotherapy, "Prof. Dr. Alexandru Trestioreanu” Institute of Oncology, \\ "Carol Davila" University of Medicine and Pharmacy, Bucharest, Romania; \\ ${ }^{3}$ General Surgery Department, "Prof. Dr. Bagdasar Arseni" Clinical Emergency Hospital, \\ "Carol Davila" University of Medicine and Pharmacy, Bucharest, Romania; \\ ${ }^{4}$ II Department of Internal Medicine, "Fundeni" Clinical Institute, \\ "Carol Davila" University of Medicine and Pharmacy, Bucharest, Romania
}

\begin{abstract}
Background/Aim: The Covid-19 epidemic has severely strained health care systems across the globe. The impacts are multiple especially for patients cared for cancer. The Covid-19 epidemic has several impacts on the management of lung cancer patients. The aim of this work was to summarize the available epidemiological data on patients diagnosed with lung cancer infected with Covid-19 and describe the different strategies to improve the management of these patients by summarizing the recommendations in this area. Patients and Methods: The Teravolt cohort is an observational multicenter registry, including patients with non-small cell cancer, small cell cancer or mesothelioma but also epithelial tumors and a diagnosis of Covid-19. The Theravolt registry indicates an unexpectedly high mortality rate in patients with thoracic malignancies with COVID-19. Results: Between March 26 and April 12, 2020, 200 patients treated in 8 countries were included. They had a performance status (PS) of 0-1 in 72\% of cases, were smokers or exsmokers in $81 \%$ of cases, had non-small cell cancer $176 \%$ of cases), were under treatment in $74 \%$ of cases, and the majority were first-line cases (57\%). The hospitalization rate was $76 \%$ and the mortality rate $33 \%$; only $10 \%$ of patients with criteria for intensive care hospitalization were admitted
\end{abstract}

This article is freely accessible online.

Correspondence to: Anca Zgura, Department of OncologyRadiotherapy, "Prof. Dr. Alexandru Trestioreanu" Institute of Oncology, "Carol Davila" University of Medicine and Pharmacy, 37 Dionisie Lupu Street, District 2, 020021 Bucharest, Romania. Tel: +40 751110005, e-mail: medicanca@gmail.com

Key Words: Lung cancer, chemotherapy, immunotherapy, Covid-19 infection, recommendations. to the intensive care. Conclusion: Data presented in this registry suggest a high mortality in patients with thoracic cancer and Covid-19. Therofere, the importance to create a safe healthcare system during Covid-19 pandemic is underlined along with the need for essential effective clinical service delivery to patients with lung cancer.

Lung cancer is the second most common cause of malignancy worldwide among both females and males. The main risk factor for lung cancer remains smoking. Lung cancer is divided in two cell types: small cell lung cancer and non-small cell lung cancer, representing 15 and $85 \%$ of all lung cancer cases. The histology and genetic profile of lung cancer are important factors for treatment choices and preventive strategies $(1,2)$.

The Covid-19 epidemic has had several impacts on the management of lung cancer patients. Tensions over care systems have led to diagnostic delays, the need to arrange for the management of systemic treatments, but also oral treatments, and finally delays in the management of surgery and radiation therapy.

It does not appear that lung cancer is an extremely important risk factor for susceptibility to Covid-19 or worsening of infection, at least not in the same way as other comorbidities such as cardiovascular disease, diabetes and chronic obstructive pulmonary disease. In contrast, it appears that when infected, patients with lung cancer have a higher risk of worsening.

\section{Patients and Methods}

Soon after the pandemic outbreak, prospective cohorts were set up to identify the characteristics of Covid-19-infected lung cancer patients. One of the first international studies was European, from Italy. The Teravolt a multicentre observational study composed of a 
cross-sectional component and a longitudinal cohort component This is an observational multicenter registry, including patients with non-small cell cancer, small cell cancer or mesothelioma but also epithelial tumors and a diagnosis of Covid-19, either confirmed by polymerase chain reaction (PCR) or with an evocative clinical picture and radiology consistent with Covid-19 pneumonia.

\section{Results}

The cohort began on January 1, 2020 and first results were published recently. Between March 26 and April 12, 2020, 200 patients treated in 8 countries were included. They had a performance score (PS) of $0-1$ in $72 \%$ of cases and were smokers or ex-smokers in $81 \%$ of cases. Cancer was mainly non-small cell cancer ( $76 \%$ of cases), while $74 \%$ of cases were under treatment in, and in their majority, they were firstline cases $(57 \%)$. The hospitalization rate is $76 \%$ and the mortality rate is $33 \%$; only $10 \%$ of patients with criteria for admission to intensive care were admitted to intensive care.

The variable studied was age, being older than 65 years $(\mathrm{HR}=1.88,95 \% \mathrm{CI}=1.00-3.72)$, smoking status, being a current or former smoker $(\mathrm{HR}=4.24,95 \% \mathrm{CI}=1.70-2.95)$, treatment modality, receiving chemotherapy $(\mathrm{HR}=2.54,1.09-6.11)$ and the presence of comorbidity $(\mathrm{HR}=2.65,1.09-7.46)$ were associated with an increased risk of death. Mortality was 32\%, only $33 \%$ continued their systemic treatment after Covid-19 infection. Interestingly, treatment with immunotherapy seems to decrease the risk of mortality $(\mathrm{OR}=0.6,95 \% \mathrm{CI}=0.5-0.97)$, perhaps due to the fact that immunotherapy has the role of stimulating the immune system. Immunotherapy has been a new standard of care for advance/metastatic lung cancer. The prominent characteristics of cancer immunotherapy is the induction of immune memory followed by endured treatment response. Immunotherapy simultaneously boosted cytotoxic $\mathrm{T}$ lymphocyte (CTL) immune responses against virus-infected and neoplastic cells (3).

\section{Discussion}

Covid-19 infection tends to be more severe in patients diagnosed with lung cancer. Abundant literature has been developed very rapidly on the various aspects of lung cancer management at the time of the Covid-19 related pandemic (4-10).

A team from Milan (11) developed, according to clinical data and therapeutic modalities, an extremely interesting support algorithm. This algorithm established from sex, PS, age, sex BMI, comorbidities, treatment or not corticosteroids, and tumor characteristics and treatments, classifies patients into 3 risk categories:

- A low-risk category that allows maintained cancer management as planned before the epidemic, delay or reduced the number of visits to the hospital, using teleconsultation tools, or using systemic oral treatments;
- An intermediate-risk category where management of the disease is systematically considered to be delayed;

- A high-risk category that requires not only acute treatment, but also closer monitoring of clinical and biological signs. In that series, the therapeutic modalities (history of surgery, history of irradiation, systemic treatment) do not appear to have an impact on severity of Covid-19 infection. The authors found no biological factor particularly significantly associated with severity (11).

The impact of the Covid-19 pandemic on lung cancer treatment. Lung cancer is associated with increased mortality and Covid-19 infection overshadows patient prognosis. Current treatment options involve surgery chemotherapy, radiotherapy, targeted therapy and immunotherapy.

All virtual meetings in the field of oncology focused on patient management during the Covid-19 pandemic. An English team (12) retrospectively analyzed 40 patients treated with durvalumab in maintenance for a locally advanced disease. They showed that a telephone consultation and a switch from administration of the treatment every 2 weeks to administration every 4 weeks is feasible and does not appear to have deleterious effects on patient safety. A study by the Institute Gustave Roussy (13) evaluated a Covid-19 infection screening strategy combining a computed tomography (CT) scan without injection and PCR samples in asymptomatic patients undergoing radiotherapy. From March 18 to May 1, 2020, among the 507 patients included in the study, 257 had CT-scan abnormalities, so $34(8 \%)$ were Covid-19 compatible (CO-RADS 3); 102 had PCR after the scan; $24 / 449$ (5.3\%) were considered Covid-19 positive: 19 with a positive PCR and 5 on the appearance of the scanner. Almost half of the patients were asymptomatic or not very symptomatic.

The challenge of Covid-19 in patients treated by chemoradiotherapy for a locally advanced cancer is also existence of differential diagnosis with other causes of radiological abnormalities like radiation-induced pulmonary fibrosis which is a common complication of thoracic radiotherapy for lung cancer $(14,15)$. Radiation-induced pulmonary fibrosis leads to irreversible destruction of lung architecture and disruption of gas exchange. Immunotherapy might simultaneously boost cytotoxic $\mathrm{T}$ lymphocyte immune response against virus-infected and neoplastic cells. This immune stimulation might cause the exacerbate the disease, but a recent study has shown the opposite that it is safe to continue continued use of PD-1 blockade during the Covid19 pandemic (16). It is very important to distinguish Covid19 pneumonia from other lung pathologies for a correct treatment and early as possible.

In Romania we have been trying to continue cancer treatments wherever possible; in cases where it was possible, we increased the period between treatment cycles, we 
reduced the time with patients in consultations and where possible we performed telephone consultations.

The effects of Covid-19 pandemic on the healthcare system affected both hospitals and patients. Due to the large number of Covid-19 patients who needed hospitalization, the reallocation of human resources reduced the number of newly diagnosed patients and access to treatment for lung cancer complications.

The Covid-19 pandemic led to postponement and cancellation of surgery. The impact of delayed cancer surgery due to the Covid-19 pandemic was analyzed in a study that reported that a three-month and six-month delay of surgery decreased the anticipated global survival obtained after surgical treatment by 19 and $43 \%$, respectively (17).

The recommendations we took into account during this period were:

- To prioritize in multidisciplinary meetings remote organizations, telemedicine or video conferencing;

- To provide for screening processes for the symptoms of Covid-19 infection before receiving patients in hospitals during the day, in conventional hospitalization and/or for the diagnostic procedures;

- To limit the exposure of the environment and family during consultations or upon arrival to hospital centers for technical examinations, radiological and endoscopic;

- To maintain a diagnostic strategy that takes into account for differential diagnosis for suspected cases of Covid-19 disease;

- To adapt the modalities of follow-up to the reality of the epidemic, in particular a reasoned economy of examination e.g. imaging, discussion of the most appropriate moment for surgical procedures, the possibility, in some cases, to perform radiotherapy on localized tumors rather than surgery if the surgical health system is energized;

- Febrile neutropenia and infection, remain major toxicities associated with myelosuppressive systemic cancer chemotherapy. According to the recommendations in patients who have an approximately $10 \%$ or higher risk for febrile, primary prophylaxis with a hematopoietic colonystimulating factors will have to be started at the first cycle and continue through subsequent cycles of chemotherapy;

- For immunotherapy, most companies have adopted longer rates for administrations, every 3,4 or 6 weeks depending on the agent used;

- For small-cell lung cancer, especially in the first line, the recommendations are to follow the deadlines for the care of these rapidly evolving patients, and for radiotherapy, to discuss modalities in order to have fewer sessions, therefore get the patient to the hospital less often.

\section{Conclusion}

The amount of knowledge on the interactions of lung cancer and Covid-19 infection has become richer, especially due to studies that included a large number of patients in multicenter. It is, therefore, important to create a safe healthcare system during the Covid-19 pandemic and it is essential to sustain effective clinical service delivery to patients with lung cancer.

\section{Conflicts of Interest}

The Authors declare that they have no competing interests in relation to this study.

\section{Authors' Contributions}

$\mathrm{BH}$ was responsible writing of the manuscript. $\mathrm{AZ}$ and $\mathrm{BH}$ were responsible for reviewing and editing of the manuscript. $\mathrm{AZ}, \mathrm{BH}$, $\mathrm{XB}$ and $\mathrm{CB}$ made substantial contributions to the conception or design of the work. RA were responsible for the critically review of the manuscript. All Authors read and approved the final manuscript.

\section{References}

1 Buccheri G and Ferrigno D: Lung cancer: Clinical presentation and specialist referral time. Eur Respir J 24(6): 898-904, 2004. PMID: 15572529. DOI: 10.1183/09031936.04.00113603

2 Larsen JE and Minna JD: Molecular biology of lung cancer: Clinical implications. Clin Chest Med 32(4): 703-740, 2011. PMID: 22054881. DOI: 10.1016/j.ccm.2011.08.003

3 Robilotti EV, Babady NE, Mead PA, Rolling T, Perez-Johnston R, Bernardes M, Bogler Y, Caldararo M, Figueroa CJ, Glickman MS, Joanow A, Kaltsas A, Lee YJ, Lucca A, Mariano A, Morjaria S, Nawar T, Papanicolaou GA, Predmore J, Redelman-Sidi G, Schmidt E, Seo SK, Sepkowitz K, Shah MK, Wolchok JD, Hohl TM, Taur Y and Kamboj M: Determinants of COVID-19 disease severity in patients with cancer. Nat Med 26(8): 1218-1223, 2020. PMID: 32581323. DOI: 10.1038/s41591-020-0979-0

4 Zhu N, Zhang D, Wang W, Li X, Yang B, Song J, Zhao X, Huang B, Shi W, Lu R, Niu P, Zhan F, Ma X, Wang D, Xu W, Wu G, Gao GF, Tan W and China Novel Coronavirus Investigating and Research Team: A novel coronavirus from patients with pneumonia in China, 2019. N Engl J Med 382(8): 727-733, 2020. PMID: 31978945. DOI: 10.1056/NEJMoa2001017

5 Knight SR, Ho A, Pius R, Buchan I, Carson G, Drake TM, Dunning J, Fairfield CJ, Gamble C, Green CA, Gupta R, Halpin S, Hardwick HE, Holden KA, Horby PW, Jackson C, Mclean KA, Merson L, Nguyen-Van-Tam JS, Norman L, Noursadeghi M, Olliaro PL, Pritchard MG, Russell CD, Shaw CA, Sheikh A, Solomon T, Sudlow C, Swann OV, Turtle LC, Openshaw PJ, Baillie JK, Semple MG, Docherty AB, Harrison EM and ISARIC4C Investigators: Risk stratification of patients admitted to hospital with covid-19 using the ISARIC WHO clinical characterisation protocol: Development and validation of the 4C mortality score. BMJ 370: m3339, 2020. PMID: 32907855. DOI: 10.1136/bmj.m3339

6 de Azambuja E, Brandão M, Wildiers H, Laenen A, Aspeslagh S, Fontaine C, Collignon J, Lybaert W, Verheezen J, Rutten A, Vuylsteke P, Goeminne JC, Demey W, Van Beckhoven D, Deblonde J, Rottey S, Geukens T, Punie K, Belgian Collaborative Group on COVID-19 Hospital Surveillance and 
the Belgian Society of Medical Oncology (BSMO)., Bafort K, Belkhir L, Bossuyt N, Colombie V, Daubresse C, Dauby N, De Munter P, Delmarcelle D, Delvallee M, Demeester R, Delefortrie Q, Dugernier T, Holemans X, Louviaux I, Machurot P, Minette P, Mokrane S, Nachtergal C, Noirhomme S, Piérard D, Rossi C, Schirvel C, Sermijn E, Staelens F, Triest F, Van Beckhoven D, Van Goethem N, Van Praet J, Vanhoenacker A, Verstraete R, Willems E and Wyndham-Thomas C: Impact of solid cancer on in-hospital mortality overall and among different subgroups of patients with COVID-19: A nationwide, population-based analysis. ESMO Open 5(5): e000947, 2020. PMID: 32978251. DOI: 10.1136/esmoopen-2020-000947

7 Rogado J, Pangua C, Serrano-Montero G, Obispo B, Marino AM, Pérez-Pérez M, López-Alfonso A, Gullón P and Lara MÁ: Covid-19 and lung cancer: A greater fatality rate? Lung Cancer 146: 19-22, 2020. PMID: 32505076. DOI: 10.1016/ j.lungcan.2020.05.034

8 Wang L, Jiang $\mathrm{M}$, Qu J, Zhou $\mathrm{N}$ and Zhang X: Clinical management of lung cancer patients during the outbreak of COVID-19 epidemic. Infect Agent Cancer 15: 56, 2020. PMID: 32983254. DOI: 10.1186/s13027-020-00322-7

9 Zhang $\mathrm{H}, \mathrm{Xie} \mathrm{C}$ and Huang Y: Treatment and outcome of a patient with lung cancer infected with severe acute respiratory syndrome coronavirus-2. J Thorac Oncol 15(5): e63-e64, 2020. PMID: 32147577. DOI: 10.1016/j.jtho.2020.02.025

10 Calabrò L, Peters S, Soria JC, Di Giacomo AM, Barlesi F, Covre A, Altomonte M, Vegni V, Gridelli C, Reck M, Rizvi N and Maio M: Challenges in lung cancer therapy during the COVID19 pandemic. Lancet Respir Med 8(6): 542-544, 2020. PMID: 32278368. DOI: 10.1016/S2213-2600(20)30170-3

11 Ciceri F, Castagna A, Rovere-Querini P, De Cobelli F, Ruggeri A, Galli L, Conte C, De Lorenzo R, Poli A, Ambrosio A, Signorelli C, Bossi E, Fazio M, Tresoldi C, Colombo S, Monti G, Fominskiy E, Franchini S, Spessot M, Martinenghi C, Carlucci M, Beretta L, Scandroglio AM, Clementi M, Locatelli M, Tresoldi M, Scarpellini P, Martino G, Bosi E, Dagna L, Lazzarin A, Landoni G and Zangrillo A: Early predictors of clinical outcomes of COVID-19 outbreak in Milan, Italy. Clin Immunol 217: 108509, 2020. PMID: 32535188. DOI: 10.1016/j.clim.2020.108509
12 Joshi K, Muhith A, Milner-watts C, Obeid M, Khakoo S, Bhosle J, Minchom A and O'brien M: 1241P Safety monitoring of adjuvant 2 weekly durvalumab for patients with stage III NSCLC: Implications for a 4 weekly regimen during the COVID-19 pandemic and beyond. Annals of Oncology 31: S805, 2020. DOI: 10.1016/j.annonc.2020.08.114

13 Sun R, Achkar S, Ammari S, Bockel S, Gallois E, Bayle A, Battistella E, Salviat F, Merad M, Laville A, Ka K, Griscelli F, Albiges L, Barlesi F, Bossi A, Rivera S, Chargari C and Deutsch E: Systematic screening of COVID-19 disease based on chest $\mathrm{CT}$ and RT-PCR for cancer patients undergoing radiation therapy in a coronavirus French hotspot. Int J Radiat Oncol Biol Phys: 2021. PMID: 33609591. DOI: 10.1016/j.ijrobp.2021.02.022

14 Souza IL, Fernandes Í, Taranto P, Buzaid AC and Schvartsman $\mathrm{G}$ : Immune-related pneumonitis with nivolumab and ipilimumab during the coronavirus disease 2019 (COVID-19) pandemic. Eur J Cancer 135: 147-149, 2020. PMID: 32585589. DOI: 10.1016/ j.ejca.2020.06.004

15 Guerini AE, Borghetti P, Filippi AR, Bonù ML, Tomasini D, Greco D, Imbrescia J, Volpi G, Triggiani L, Borghesi A, Maroldi R, Pasinetti N, Buglione M and Magrini SM: Differential diagnosis and clinical management of a case of COVID-19 in a patient with stage III lung cancer treated with radiochemotherapy and durvalumab. Clin Lung Cancer 21(6): e547e550, 2020. PMID: 32527714. DOI: 10.1016/j.cllc.2020.05.027

16 Luo J, Rizvi H, Egger JV, Preeshagul IR, Wolchok JD and Hellmann MD: Impact of PD-1 blockade on severity of COVID19 in patients with lung cancers. Cancer Discov 10(8): 1121-1128, 2020. PMID: 32398243. DOI: 10.1158/2159-8290.CD-20-0596

17 Sud A, Jones ME, Broggio J, Loveday C, Torr B, Garrett A, Nicol DL, Jhanji S, Boyce SA, Gronthoud F, Ward P, Handy JM, Yousaf N, Larkin J, Suh YE, Scott S, Pharoah PDP, Swanton C, Abbosh C, Williams M, Lyratzopoulos G, Houlston R and Turnbull C: Collateral damage: The impact on outcomes from cancer surgery of the COVID-19 pandemic. Ann Oncol 31(8): 1065-1074, 2020. PMID: 32442581. DOI: 10.1016/j.annonc.2020.05.009

Received February 19, 2021

Revised March 24, 2021

Accepted March 26, 2021 